\title{
Career Satisfaction and Adult Attachment Style Among Working Adults: Evidence from Turkey
}

\author{
Ryan Macey Wise ${ }^{1}$ D $\cdot$ Burcu Alsan ${ }^{1} \cdot$ Elham Taleb $^{1}$
}

Accepted: 1 February 2022 / Published online: 17 February 2022

(c) Associação Brasileira de Psicologia 2022

\begin{abstract}
This study examined the relationship between employee attachment style, organizational factors, and career satisfaction among adult employees in Turkey. A total of 288 (167 female, 121 male) employees working in two sectors participated in this study with an age range of 22 to 60 years $(M=31.8, S D=7.4)$. Adult attachment styles were measured with the Relationship Scales Questionnaire and career satisfaction was assessed with the Career Satisfaction Scale. A series of multiple hierarchical regression analyses and correlational analyses were conducted to examine the relationship between career satisfaction, attachment style, and organizational factors. The results revealed that organizational factors and attachment styles are important predictive measures of career satisfaction. A unique finding was the positive relationship between dismissing attachment and career satisfaction, a result we interpret as an outcome related to economic insecurity and crisis. Both theoretical and applied implications of the results are discussed and suggestions for future directions are addressed.
\end{abstract}

Keywords Attachment · Career satisfaction · Organizational psychology · Turkey

\section{Career Satisfaction and Adult Attachment StyleAmong Working Adults: Evidence from Turkey}

Determining predictors of career satisfaction is important for evaluating employee success, motivation, and performance, and is a key element in talent development (Bargsted et al., 2021; Heslin \& Turban, 2016). Previous research has mostly concentrated on job-related factors such as job security, perceptions of fairness, and reward systems (Iqbal et al., 2020; Yean and Yahya 2013). Despite individual

Ryan Macey Wise

ryan.wise@bilgi.edu.tr

Burcu Alsan

burcualsan87@gmail.com

1 Department of Psychology, Istanbul Bilgi University, Istanbul, Turkey 
differences having received extensive attention (Barrick \& Mount, 1991; Hogan \& Holland, 2003), there has been little empirical focus on investigating the relationship between adult attachment patterns and career satisfaction (Sumer \& Knight, 2001). Much of the literature concerning adult attachment style, attachment behaviors, and their relationship to various organizational outcomes has been limited to samples recruited from undergraduate university students and focuses on career choices, rather than occupational experience (Meredith et al., 2007).

Rooted in ethology and evolutionary theory, attachment theory (Bowlby, 1986) maintains that infants pursue strategies to maintain within close proximity to primary caregiving figures as an adaptive response to dependency and to promote survival. It is during the attachment period that infants develop internal working models in terms of their relationships with a primary attachment figure who serves as a secure base and offers protection and support in times of threat (Bowlby, 1986). An individual's attachment style is internalized into wide regulatory strategies that guide an individual's sense of self and interpersonal relationships.

Attachment styles represent internal working models enduring into adulthood (Chui \& Leung, 2016; Cobb \& Davila, 2009; Hazan \& Shaver, 1987; Sheinbaum et al., 2015). Main and Hesse (1990) defined primary conditional attachment strategies as those that allow an individual to respond promptly and sensitively to an individual's attachment signals. Primary strategies included using attachment figures as a secure base for activities such as seeking and keeping intimacy, protesting separation, and engaging in environmental exploration (Hazan \& Shaver, 1994). Internal working models influence cognition and behavior in later relationships and contexts as attachment is transferred from parental figures to adult peers and significant others, and informs both interpersonal relationships and environmental interactions across a broad range of settings. Through internal working models, attachment influences various behaviors including coping skills, the feeling of personal worth, and quality of adaptation to environmental requirements (Mikulincer, 1995), including adult workplace settings (Harms, 2011; Richards \& Hackett, 2012).

Blustein, et al. (1995) suggested that work environments required coping with novel situations and adapting to change, and exhibited a psychological and interpersonal dynamic paralleling infant environment interactions. Starting a job is a socialization process requiring employees to form new relationships and nurture existing ones. Lowman (1993) further stated that significant interpersonal challenges were presented in the workplace, and therefore the workplace corresponded to a risky environment for many employees and that adjustment and employee well-being were partly informed by adult attachment style. For example, insecurely attached individuals are reported to be more vulnerable to change due to their less successful adaptations to stressful situations (Hudson, 2013). Secure attachment has been correlated with adaptation and work-related adjustment (Blustein et al., 1995; Chen et al., 2021), leadership (Mayseless \& Popper, 2019; Underwood et al., 2016), progress in career decision making (Hazan \& Shaver, 1990), work-related exploration activities, and career exploration (Littman-Ovadia et al. 2013).

Individual differences in attachment relationships have important implications for orientation and attitudes toward work (Neustadt \& Furnham, 2006). The exploration system which is developed in infancy is largely dependent on the availability of 
the attachment figure (Ainsworth et al., 1978). Empirical studies have demonstrated that attachment to parents is associated positively with environmental exploration (Blustein et al., 1994; Elliot \& Reis, 2003). As the infant attachment process supports infant exploration, adult attachment supports work activity as adults explore novel employment settings in order to develop competency in interacting with the physical and social environment (Fraley \& Shaver, 2008). Secure attachment has been associated with freely exploring work environments and greater work satisfaction. Insecure attachment styles hindered efficient productivity and time-dependent task completion (Hazan \& Shaver, 1990). The sub-categories of insecure attachment exhibit variation in predicting job success and determining employee-workplace fit across different components of the workplace environment, including autonomy, collaboration, goal setting, and conflict resolution (Littman-Ovadia et al., 2013).

There are three insecure attachment styles: fearful, dismissing, and preoccupied (Mikulincer \& Shaver, 2007), and each has been differentially related to workrelated outcomes (Sheinbaum et al., 2015), including job searching (Leenders et al. 2017), workplace satisfaction (Scrima et al. 2015), and leadership (Boatwright et al., 2010). Insecure attachment style classifications are centered around two relational dimensions associated with dealing with distress in interpersonal relationships: anxiety and avoidance. Insecure-fearful attachment demonstrates a high level of anxiety concerning relationships and distancing from others to prevent or minimize this anxiety. Insecure-dismissing involves attempts at avoidance of anxiety through reliance on self-sufficiency and a minimization of distress. Insecure-preoccupied attachment demonstrates less avoidance, but more anxiety and distress in relationships (Sheinbaum et al., 2015; Vîrgă et al., 2019).

Attachment styles are associated with differential outcomes related to economic precarity, with secure attachment demonstrating a relationship with more positive outcomes among low-income adults, whereas insecure attachment is associated with more deleterious effects (Mills-Koonce et al., 2011). However, although limited, research suggests that insecure-dismissing attachment demonstrates a protective function in regard to traumatic events (Bogaerts et al., 2009), partly through the mechanism of distancing and a positive view of self. Similarly, posttraumatic symptoms have been reported to demonstrate a negative relationship with secure and insecure-dismissing attachment but not with insecure-fearful and insecure-preoccupied (Muller et al., 2000), suggesting that the shared self-view may protect against negative outcomes related to traumatic events and situations.

\section{Career Satisfaction}

Career satisfaction is an individual's perception of one's own career achievement with reference to self-determined standards (Nabi, 2001, 2003). Organizational factors are strongly associated with career satisfaction, including income, status, promotion, development opportunities, organizational culture and commitment, work-life integration, employer recognition, and opportunity for advancement (Barnett \& Bradley, 2007; 2008; Illies, \& Reiter-Palmon, 2020; Johnson et al., 2020; Krueger et al., 2002; Park, 2018). A consistent finding in the organizational literature is that 
person-workplace fit predicts job satisfaction and employee organizational commitment (Klaic et al., 2018; Player et al., 2017; Sylva et al., 2019), with environment fit being considerably influenced by internal psychological factors and dispositions among employees, including personality (Steel et al., 2019), self-efficacy (Perera et al., 2018), and temperament (Jaracz et al., 2017).

Less studied, but also predictive of career satisfaction is adult attachment patterns. Regarding career satisfaction, empirical evidence suggests that adult attachment is a predictor of employee-job dynamics and this relationship demonstrates conceptually similar characteristics as early childhood attachment experiences. Employees show differential responses to workplace environment experiences, including hierarchical navigation, interpersonal relationships, and opportunity seeking that are conceptually similar to young children exploring their proximal environment. Based on this conceptualization, it would be predicted that securely attached individuals would demonstrate greater work exploration, including seeking out career opportunities, creating and developing strong interpersonal relationships, and managing negative affect more adeptly than insecurely attached individuals, and as a consequence, would show higher levels of career and job satisfaction.

Attachment style influences employee work-related behaviors, attitudes, and responses (Harms, 2011; Hazan \& Shaver, 1990; Richards \& Schat, 2011), and demonstrate that secure attachment facilitates work-related exploration activities, being positively associated with career exploration (Littman-Ovadia et al. 2013), confidence in receiving good evaluations by colleagues (Blustein et al., 1995), ability to negotiate (Ketterson \& Blustein, 1997), and progress in career decision making (Hazan \& Shaver, 1990). Insecure attachment, on the other hand, is correlated with lower levels of productive behaviors, organizational commitment (Mikulincer \& Shaver, 2007), and job satisfaction (Hazan \& Shaver, 1990).

Securely attached individuals depend on basic guidelines of the attachment system such as engaging in instrumental action, asking for others' support, and expectation for successful management of the situation (Mikulincer, 1998). They tend to engage in support-seeking behaviors during potential overload in the workplace and are more likely to experience lower levels of workplace stress (Richards \& Schat, 2007) and demonstrate a greater ability to redefine stressful situations as opportunities for growth (Mikulincer \& Florian, 1995). These individuals have confidence in others' good intentions and actions (Bartholomew \& Horowitz, 1991).

Secure attachment has been associated with trust in line managers, peers, and top management (Simmons et al., 2009) as they are prone to share their goals not because it creates a sense of security, but to gain intimacy with them (Mikulincer, 1998). Thanks to their relationship with coworkers, securely attached individuals build a social support system at work and in private life (Simmons et al., 2009) and they are less likely to register psychosomatic and physical illnesses (Hazan \& Shaver, 1990). Secure attachment is related to a reduced focus on rejection and poor performance compared to insecurely attached employees.

Individuals demonstrating a preoccupied adult attachment style demonstrate greater concerns about rejection and performance evaluation (Hazan \& Shaver, 1990). Moreover, preoccupied attachment style has been associated with greater 
worry about workplace relationships and report less job satisfaction, more stress, and greater burnout (Fraley \& Shaver, 2008) and are less likely to engage in emotion-based coping strategies during stressful situations. Dismissing and fearful attachment styles are characterized by distance in the relationship, low levels of emotional intensity, little reliance on partners, inattention to distress indicators, and greater reticence in sharing personal information (Monteoliva et al., 2012). Fearful attachment is related to the work environment being conceptualized as an opportunity to avoid social interaction (Hardy \& Barkham, 1994), and to maintain psychological independence (Rholes \& Simpson, 2004). Fearful and dismissing attachment is associated with lower levels of workplace trust (Cranshaw \& Game, 2010). Mikulincer and Florian (1995) reported that insecure attachment is related to less likelihood of engaging in support-seeking behaviors and greater distance between self and others (Erez, et al., 2008; Geller \& Bamberger, 2009) leading to low levels of workplace dissatisfaction (Hardy \& Barkham, 1994).

Findings related to organizational success and career performance and satisfaction, however, do not indicate only negative relationships between insecure attachment patterns and outcomes. Insecure-dismissing attachment, which shares important characteristics related to self-image and ego strength with secure attachment, has been associated with successful outcomes at work and in career settings. Ein-Dor et al. (2012) reported evidence that in careers that reward independence and autonomy, and which provide limited immediate support, an avoidant attachment was associated with positive outcomes and greater career success. Insecure-dismissing attachment may also serve to promote resilience in situations and environments where individuals are exposed to chronic sources of stress associated with social inequalities (Bartley et al, 2007) primarily as a defensive mechanism of ego protection.

Sheinbaum et al. (2015) reported that attachment style is related to affect, social functioning, and cognitive appraisals. Individuals, for example, with dismissing attachment were more likely to show fewer positive states of well-being and endorse a preference to be alone compared to securely attached individuals. A fearful attachment was related to having more stress and anxiety and a greater likelihood to perceive rejection from others. Evidence suggests that when presented with a choice, individuals tend to select careers and jobs that are seen as reflecting personality characteristics (Alkhelil, 2016). Attachment style is also related to self-disclosure, trust, and group functioning (Pistole, 1993; Shechtman \& Rybko, 2004).

These behavioral and perceptual differences manifest not only in family and group dynamics, but also inform workplace experiences of individuals, including leadership (Manning, 2003), resilience (Bartley et al, 2007), and the ability to trust others (Vasquez et al., 2002). Related to satisfaction measures, attachment has been found to predict general life satisfaction (Gnilka et al., 2013; Wright \& Perrone, 2010) and workplace and career satisfaction (Krauz et al., 2001; Oh \& Sung, 2011; Tziner et al., 2014). 


\section{Attachment, Gender, and Career Satisfaction}

One robust research finding in the organizational psychology literature is that women report greater job satisfaction than do men, and this finding has been replicated across different industries, organizations, and sociocultural contexts (Redmond \& McGuinness, 2020). Various explanations and theories have been proposed to account for this finding. One plausible explanation is likely women's greater focus on maintaining family-work balance compared to men, especially in cultures with a greater gender-based division of labor, and this finding may show greater representation at higher-income levels (Redmond \& McGuinness, 2017, 2020). Cultural definitions of gender roles and norms surrounding appropriate and permitted expressions also suggest that men may be more willing to express displeasure than women (Hodson, 1989. In Turkey, however, this relationship may point in the opposite direction, as women have been reported to experience job overload as they attempt to balance work demands and primary care for children and the family (Bozkurt et al., 2011). Additional factors undermining job and career satisfaction for women in Turkey include patriarchal attitudes toward women's formal employment, limited social welfare programs, and limited vertical job mobility (Kağnıcıoğlu, 2017).

Gender is also related to child-rearing practices in Turkey, with male and female children experiencing different parenting practices, especially in the domains of control and autonomy (Sunar, 2009; Telsiz, 1998). These differences are to an extent generational in nature and overlap with family demographic variables, including income, mothers' employment, education, and geography (Sunar, 2009). While there is limited research on gender differences in attachment style as a function of parenting practices, the extant research among Turkish samples does suggest that parenting does have a moderate effect on the development of attachment, with authoritative parenting associated with higher scores on measures of secure attachment (Doinita \& Maria, 2015).

\section{Current Study and Rationale}

The purpose of this study was to examine the role of attachment styles in the workplace and their relationship with the career satisfaction of employees in various private organizations in Turkey. The private employment sector in Turkey represents a unique environment characterized by economic upheaval and precarity, and greater emphasis on collectivistic relational dynamics than represented in studies on attachment and work in Western societal contexts. Previous research on the relationship between adult attachment patterns and workplace experiences, career satisfaction, and employee well-being has primarily focused on samples drawn from societies and cultures scoring high on values associated with individualism and with greater economic stability (Hofstede, 2011; Simpson \& Rholes, 2017). Cross-cultural research examining individuals from diverse societies suggests that although attachment theory demonstrates cross-cultural application, it does so with considerable cultural variation (Lin et al., 2017) as a function of the 
cultural emphasis on the individualism-collectivism continuum and is related to economic development level (Strand et al., 2019).

Turkey scores lower on measures of individualism compared to the USA, other English-speaking countries, and most Western European countries, socalled WEIRD societies (Western, educated, industrialized, rich, and democratic) (Henrich et al., 2010; Hofstede, 2011). In collectivist countries, relationships are perceived as having greater importance and are more highly valued than in more individualistic-oriented societies (Sunar \& Fişek, 2005). Thus, it would be likely that variation in attachment relationships and outcomes would be differently experienced in Turkey, and by extension, across diverse cultures. For example, Agishtein and Brumbaugh (2013) reported that attachment anxiety was associated with the country of origin, cultural values, and ethnicity. Although limited research explores the role of cultural valuation systems on attachment patterns, research demonstrates the utility of including a more diverse set of cultural experiences (Butler et al., 2007; Harma \& Sümer, 2016; Rothbaum et al., 2000; Sorensen \& Oyserman, 2010). Moreover, the historic economic crises in Turkey, and the ongoing (2021-2022) economic disruption due to the COVID-19 pandemic, which includes economic precarity, high inflation, and employment disruption, all macro-level variables that are shared across developing and emerging economies, suggest the necessity to pursue this investigation so as to confirm previous findings conducted in primarily Western developed countries.

Previous research suggests that career and occupational choice reflects inner working structural components reflecting person-level variables, including temperament, personality, and dispositional traits (He et al., 2021; Ripski et al., 2011; Sui et al., 2021; Yusof et al., 2020). This study, therefore, includes a separate investigation exploring attachment dimensions relative to employee selection of the job sector, as different sectors of employment, have different expectations for workers (Furnham \& Fudge, 2008; van Dolen et al., 2002).

This study extends the literature on attachment styles and how they relate to work experience and career satisfaction in a culture that places high importance on the cultural value of collectivism (Kagitcibasi \& Ataca, 2005; Kagitcibasi et al., 2005). Building on previous research findings demonstrating a relationship between organizational factors (employment time, position tenure, and income) and career and workplace satisfaction (Aryee \& Luk, 1996; Cerci \& Dumludag, 2019; Kara et al., 2018; Martínez-León et al., 2018) this study examined structural and remunerative factors. Beyond these factors, the role of attachment patterns in the quality and nature of interpersonal relationships and person-environment fit suggests that as a domain of relational experience, workplace experiences and career satisfaction would be experienced differently by individuals scoring higher on measures of secure and insecure-dismissing attachment through the mechanism of ego protection (Hayden et al., 2017; Richards \& Schat, 2011; Ronen \& Zuroff, 2017; Vîrgă et al., 2019). Based on previous studies highlighting the role of gender in explanatory models of career and job satisfaction, this study includes an analysis of gender in relation to both career satisfaction and attachment. Based on these considerations, the following hypotheses guided the current study. 
Hypothesis 1: Attachment style will predict career satisfaction over and beyond the influence of employee background and organizational factors, with both secure attachment and insecure attachment—dismissing associated with greater career satisfaction.

Hypothesis 2: Gender will demonstrate an interaction effect with organizational factors and sector in predicting career satisfaction.

\section{Methods and Materials}

Ethical Compliance.

After receiving university ethical permission, participants completed an informed consent waiver indicating their voluntary participation in the study. Participants were asked to answer demographic questions and then a series of questions relating to their working and employment situation, including salary, employment tenure, sector, and experience in their current position. Next followed the measure of attachment and career satisfaction. The participants were recruited using a non-random convenience sampling technique. An online link was distributed through business and social network platforms using SurveyMonkey, an online cloud-based survey software program.

\section{Participants}

The current study included 298 employees working in different sectors including management consultancy, retail, and consumer goods in Turkey. Univariate and multivariate outlier analysis determined four outliers, which were excluded from the analysis. There was 167 female (58\%) and 121 male (42\%) participants. Participants ranged from 22 to 60 years of age $(M=31.8$ years, $S D=7.4)$. The education level varied from doctorate degree to associate degree. The greater part of the participants $(n=153,53.1 \%)$ had undergraduate degrees, very few $(n=10,3.5 \%)$ had an associate degree, $36.1 \%$ of the participants $(n=104)$ had a graduate degree, $7.3 \%$ of the participants $(n=21)$ had a doctorate degree. The work experience of the participants varied, with $22 \%$ of the participants having 1-3 years of work experience and $16 \%$ having more than 15 years. The greater part of the participants $(35.8 \%)$ had been at their current position for 1-3 years.

\section{Main Sector}

Workplace environment was assessed by asking individuals to indicate in which sector they were employed and to indicate for how long they had been employed in their current sector. Employment sectors were divided into two main sectors based on the existing literature (Kenessey, 1987). The first grouping included participants employed in the secondary sector where raw materials are produced and processed into manufactured goods and products. Sub-sectors of the secondary sector include automotive, construction, energy, retail and consumer goods, pharmaceutical, and 
chemicals. The second grouping was the service sector that involved the selling of services and skills. Sub-sectors of the services sector are management consultancy, logistics, information technology, and finance (Kenessey, 1987).

\section{Attachment Styles}

Attachment styles were assessed with the Relationship Styles Questionnaire (RSQ; Griffin \& Bartholomew, 1994). The RSQ is a 30-item self-report questionnaire that measures general orientations to close relationships on a 7-point Likert scale, with response options ranging from 1 (Not at all like me) to 7 (Very much like me). The RSQ was adapted to Turkey by Sümer and Güngör (1999) and most recently, Deveci Şirin and Şen Doğan, (2021) reported a reliability coefficient of 0.78 for the total RSQ in a Turkish sample. In the current study, attachment subscales had acceptable reliability coefficients (Cronbach's alphas), ranging from 0.53 to 0.78 .

\section{Career Satisfaction}

Career satisfaction was assessed using the Career Satisfaction Scale (CSS) developed by Greenhaus et al. (1990). The scale was translated to Turkish and back-translated to English by two individuals fluent in both languages and a confirmatory factor analysis was conducted to assess the factor structure and reliability of the Turkish translation. The CSS consists of 5 items with 7-point Likert-type scales ranging from 1 (strongly disagree) to 7 (strongly agree). This scale has been widely used in previous literature (Abele \& Spurk, 20,011 Graves et al., 2012) and has demonstrated high levels of reliability (Nae \& Choi, 2022; Spurk et al., 2011, 2015) across samples drawn from different cultures and societies (Krauz et al., 2001; Meredith et al., 2007; Onadiran \& Arogundade, 2021; Tziner et al., 2014; Wright et al., 2017).

\section{Factor Analysis}

As the CSS had not previously been translated to Turkish, confirmatory factor analysis (CFA) was conducted to determine the factor structure of the scale. Initial analysis indicated that all five CSS items demonstrated intercorrelations greater than 0.6. The Kaiser-Meyer-Olin measure of sampling adequacy was 0.85 , above the recommended value of 0.6 (Kaiser, 1974), and Bartlett's (1954) test of sphericity was significant $\left(\chi^{2}(10)=1146.04, p<0.05\right)$, indicating a non-random correlation matrix. Both indices indicate the appropriateness of using factor analysis to determine the factor structure of the CSS. The initial eigenvalues indicated one factor explained $75 \%$ of the variance and yielded one component. All five variables are loaded on one factor at or above 0.80 . Since there was only one factor, there was no rotation. Results of the CFA indicate the Turkish translation of the CSS demonstrated acceptable psychometric properties and was an appropriate measure of career satisfaction in a Turkish sample. See Table 1. 
Table 1 Factor Loadings for the Turkish Translation of the Career Satisfaction Scale (CSS)

\begin{tabular}{lll}
\hline & Component Loading & Communality \\
\hline Item 1 & 0.90 & 0.81 \\
Item 2 & 0.93 & 0.86 \\
Item 3 & 0.75 & 0.56 \\
Item 4 & 0.90 & 0.81 \\
Item 5 & 0.84 & 0.70 \\
\hline
\end{tabular}

\section{Data Analytic Strategy}

All collected responses were coded and analyzed using the SPSS statistical analysis software program (IBM Corp. Released 2013. IBM SPSS Statistics for Windows, Version 22.0. Armonk, NY: IBM Corp.). A post hoc power analysis using G*Power (Faul et al., 2007) to determine the power of the regression analysis was conducted. A baseline sample size of 300 participants with 10 predictor variables was used for the determination of power. The recommended effect sizes are: 0.02 (small effect), 0.15 (medium effect), and 0.35 (large effect) (Cohen, 1977). The alpha level used for all analyses in the study was $p=05$. The post hoc analyses revealed the statistical power for this study exceeded 0.99 for the detection of a moderate to large effect using conventional standards (0.80), indicating sufficient power.

\section{Results}

The scores on each variable were computed and reliability coefficients were calculated. All scales and subscales had acceptable reliability coefficients (Cronbach's alphas) ranging from 0.53 to 0.96 (for reference, see: Sürücü \& Maslakç1, 2020). Table 2 shows the means and standard deviations for the RSQ and CSS.

Table 2 Means and Standard Deviations for Relationship Styles Questionnaire (RSQ) and Career Satisfaction Scale (CSS)

\begin{tabular}{lll}
\hline Scale & $M$ & $S D$ \\
\hline RSQ & & \\
Secure & 3.24 & 0.97 \\
Fearful & 3.79 & 0.86 \\
Preoccupied & 4.08 & 0.93 \\
Dismissing & 4.57 & 1.39 \\
CSS & & \\
Item 1 & 4.69 & 1.62 \\
Item 2 & 4.70 & 1.62 \\
Item 3 & 4.19 & 1.71 \\
Item 4 & 4.80 & 1.57 \\
Item 5 & 4.70 & 1.51 \\
\hline
\end{tabular}




\section{Correlational Analyses}

Correlations were computed among the background characteristics and career satisfaction. Results indicated that participant career satisfaction was positively and significantly correlated with salary $(r=0.16, p<0.05)$ and education $(r=0.28$, $p<0.05)$. No significant correlation was found between career satisfaction and age, marital status, position experience, or work experience.

Hypothesis 1: Attachment style will predict career satisfaction over and beyond the influence of employee background and organizational factors, with both secure attachment and insecure attachment-dismissing associated with greater career satisfaction.

To examine the unique contribution of organizational characteristics and attachment style in the explanation of career satisfaction, a hierarchical multiple regression analysis was performed in three steps. Variables that explain career satisfaction were entered in two steps. In step 1, career satisfaction was the dependent variable, and (a) age (b) marital status, and (c) educational level were the independent variables. In step 2, organizational variables (salary, position experience, work experience) were entered into the step 1 equation. In step 3, scores on the four attachment styles were entered into the equation. Before the hierarchical multiple regression analysis was performed, the independent variables were examined for collinearity. Results of the variance inflation factor (all less than 2.0), and collinearity tolerance (all greater than 0.64 ) suggest that the estimated $\beta$ s are well established in the following regression model.

The hierarchical regression analysis for career satisfaction revealed that, at stage one, demographic variables did not contribute significantly to the regression model, $R^{2}=$. 005, $F(3,251)=0.384, p>0.01$ and accounted for $0.7 \%$ of the variation in career satisfaction. At stage two, demographic and organizational variables also did not contribute to the regression model, $R^{2}=.03, F(6,248)=1.505, p>0.01$ and accounted for $1 \%$ of the variation in career satisfaction. Finally, at stage three, adding attachment styles to the model contributed significantly to the regression model, $R^{2}=$. 09, $F(10,244)=2.440, p<0.01$ and accounted for $5 \%$ of the variation in career satisfaction. However, not all of the predictors are significant in the analysis. According to these results, when all ten independent variables were included in stage three of the regression model, salary, dismissing attachment style and secure attachment style were significant predictors of career satisfaction. The summary of the hierarchical analysis of variables predicting career satisfaction can be seen in Table 3.

Hypothesis 2: Gender will demonstrate an interaction effect with organizational factors and sector in predicting career satisfaction.

To examine Research Question 2, a $2 \times 2$ factorial analysis of variance (ANOVA) was conducted with the employment sector and gender entered as predictor variables and scores on the secure attachment measure entered as the 
Table 3 Summary of Hierarchical Regression Analysis for Variables Predicting Career Satisfaction

\begin{tabular}{|c|c|c|c|c|c|}
\hline Variables & $\beta$ & $t$ & $R$ & $R^{2}$ & $\Delta R^{2}$ \\
\hline Step 1 & & & 0.06 & 0.005 & -0.007 \\
\hline Education Level & 0.06 & 0.36 & & & \\
\hline Age & -0.004 & -0.30 & & & \\
\hline Marital Status & 0.20 & 0.94 & & & \\
\hline Step 2 & & & 0.18 & 0.03 & 0.01 \\
\hline Education Level & 0.05 & 0.28 & & & \\
\hline Age & -0.01 & -0.64 & & & \\
\hline Marital Status & 0.17 & 0.74 & & & \\
\hline Salary & 0.54 & $2.72 *$ & & & \\
\hline Position Experience & -0.16 & -0.65 & & & \\
\hline Work Experience & -0.03 & -0.14 & & & \\
\hline Step 3 & & & 0.30 & 0.09 & $0.05^{*}$ \\
\hline Education Level & 0.03 & 0.21 & & & \\
\hline Age & -0.01 & -1.13 & & & \\
\hline Marital Status & 0.16 & 0.69 & & & \\
\hline Salary & 0.54 & $2.74^{*}$ & & & \\
\hline Position Experience & -0.07 & -0.30 & & & \\
\hline Work Experience & -0.05 & -0.19 & & & \\
\hline Fearful & -0.05 & -0.37 & & & \\
\hline Dismissing & 0.32 & $2.79 *$ & & & \\
\hline Preoccupied & 0.11 & 0.98 & & & \\
\hline Secure & 0.32 & $2.22 *$ & & & \\
\hline
\end{tabular}

$* p<0.05$.

dependent variable. Prior to the data analysis, the data were screened for outliers and normality of distribution. There were no outliers and a test of kurtosis and skewness indicated no serious departures from normality (all coefficients had values of less than 1). Levene's test for homogeneity of group variance was nonsignificant.

A 2 X 2 ANOVA was used to examine scores on secure attachment by gender and employment sector (secondary and service). There was not a statistically significant interaction effect $(F=1.65, p>0.05)$ or main effect for the sector $(F=0.91, p>0.05)$. There was a statistically significant main effect for gender $(F=8.58, p<0.00)$. Male participants had a higher score on secure attachment $(M=4.60, S D=0.81)$ than female participants $(M=4.32, S D=0.84), \mathrm{d}=0.34$. For fearful attachment, there was no interaction effect $(F=0.69, p>0.05)$ or effect of the sector $(F=1.33, p>0.05)$. There was a statistically significant main effect for gender $(F=5.59, p=0.02)$, with female participants scoring higher $(M=3.61, S D=1.16)$ than male participants $(M=3.26, S D=1.12), d=-0.30$.

There was no significant interaction $(F=0.97, p>0.05)$ or main effect for either gender $(F=1.46, p>0.05)$ or sector $(F=0.86, p>0.05)$. Similarly, no interaction effect was reported for insecure-preoccupied attachment $(F=0.48$, 
$p>0.05)$, and both gender $(F=0.44, p>0.05)$ and sector $(F=0.41, p>0.05)$ were nonsignificant predictors. There was no main effect for insecure-dismissing attachment $(F=0.62, p>0.05)$. An independent sample $t$ test was conducted to determine whether there existed a significant difference between females and males in terms of career satisfaction. Results indicated that the mean career satisfaction score of females was $4.54(S D=1.43)$ and was not significantly different than that of males $(M=0.71, S D=1.33), t(286)=1.03, p=0.30$.

\section{Discussion}

The purpose of this study was to investigate the effects of attachment styles and organizational factors within a cultural and social context differing from the prevalent environments in which this relationship has been researched. Specifically, cultures scoring highly on measures of collectivism suggest the possibility of different relationships between attachment and workplace satisfaction (Strand et al., 2019). Additionally, workplace precarity and economic insecurity characterizing many developing and emerging economies, especially during the ongoing COVID-19 pandemic, suggests the importance of further contextualization (Anh et al., 2019). To this end, the current study examined adult attachment styles and career satisfaction of employees in private organizations in Turkey.

Hypothesis 1: Attachment style will predict career satisfaction over and beyond the influence of employee background and organizational factors, with both secure attachment and insecure attachment—dismissing associated with greater career satisfaction.

In the first step of the regression analysis, none of the participant background characteristics significantly predicted career satisfaction, while in the second step, employee salary exhibited a significant positive relationship. The latter finding is consistent with previous research (Faupel-Badger et al. 2017), although importantly, absolute salary may demonstrate less predictive ability than perceived salary relative to similarly employed individuals (Hammami et al., 2020). The results of the analysis for the relationship between attachment style and career satisfaction revealed that secure attachment and insecure-dismissing attachment were both positively and significantly associated with greater levels of career satisfaction. Insecure-fearful and insecure-preoccupied subscales were not significant.

Findings on the secure attachment dimension are consistent with the literature reporting that higher levels of secure attachment predict career satisfaction, and more generally, life satisfaction (Chris et al., 2009; Gould \& Penley, 1984; LévyGarboua \& Montmarquette, 2004; Nickerson \& Nagle, 2005; Sumer \& Knight, 2001; Yang et al., 2008). One possible explanation for the consistent finding is that people with secure attachment experience positive and healthy interpersonal relationships that include trust, reciprocal sharing, and mutual support (Karapinar, 2015; Leiter et al., 2015; Simpson and Rholes 2017). Considering that social capital, which includes personal relationships, is strongly correlated with life satisfaction 
(Amati et al. 2018), it is expected that individuals higher in secure attachment would evince greater career satisfaction. These results support the centrality of personal relationships, both inside and outside work, in general well-being and domain-general life satisfaction (Moghadam et al., 2016; Sharif et al., 2021; Temiz \& Comert, 2018). One possible explanation for the current finding is that adult attachment has been linked to work balance, with individuals exhibiting secure attachment in adulthood better able to experience greater levels of positive work-life balance (Sumer \& Knight, 2001).

The results related to insecure-dismissing attachment suggest a novel finding that seems to reflect larger macro-level factors characteristic of developing and emerging economies, including Turkey, and differing from the economic context of previous research that has primarily studied workers from developed economies (Zhang et al. 2021). Cranshaw and Game (2010) found that insecure-dismissing and insecure-fearful attachment dimensions were associated with lower levels of career satisfaction and trust of others. However, they also found that the insecure-dismissing attachment style had similar work satisfaction levels in terms of job security and opportunities for learning compared with securely attached individuals. According to Bartholomew and Horowitz (1991), there is a similarity between dismissing and secure attachment patterns. Both attachment forms are categorized as having a positive sense of self and internal working model and exhibit more constructive internal regulatory mechanisms.

Correspondingly, the self-perception and attributional style characteristic of insecure-dismissing attachment may lead to positive explanatory mechanisms associated with workplace satisfaction. In the current economic context of Turkey, it is suggested that aspects of the dismissing attachment pattern may prove protective for workers when faced with workplace challenges and larger macro-level economic insecurity. Turkey has experienced multiple economic crises over the last 20 years (Cömert \& Yeldan, 2018; Susam \& Bakkal, 2008), with corresponding ramifications for employees, including the potential of job loss, income devaluation, and limits on freedom, and these crises have only intensified during the ongoing COVID-19 pandemic (Özdin \& Bayrak Özdin, 2020) These economic crises have brought about long-lasting effects on organizations and employees characterized by ambiguity and stress.

Additionally, many organizations in Turkey do not have settled procedures and processes for career management systems (Hay Group 2014). Therefore, employees with a positive self-image related to career management and workplace dynamics, including in the perception of income, status loss, promotion or demotion, and job opportunity, would potentially demonstrate greater resiliency. Studies in higherincome cultures scoring higher on measures of individualism report a negative relationship between insecure-dismissing attachment and resiliency (Fraley et al., 1998; Galatzer-Levy \& Bonanno, 2013). However, research evidence suggests that individuals that engage in repression related to negative stimuli show lower levels of response to negative events and, correspondingly, experience less negative affect (Myers, 2000). While repression is associated with numerous deleterious health outcomes, in the face of high levels of economic dysfunction, repression may serve individuals to help blunt the negative experiences they face. 
Research examining coping strategies in stressful conditions suggests that repressing emotions or experience is a frequently employed defensive mechanism. For example, Palomar (2008), reports that individuals living in poverty and lower socioeconomic statuses (SES) show different coping mechanisms, including greater adoption of avoidance and minimization strategies, compared to higher SES individuals. Although sub-optimal, research suggests that repression is related to greater resilience for individuals when confronted with traumatic events (Coifman et al., 2007). Considering the context within which this study was conducted, it is probable that repeated economic crises, as has happened and continue (e.g., COVID-19 pandemic) to happen in Turkey, and also across the developing world, with the concomitant effects of employment instability and precarity, would serve as an ongoing traumatic experience for many individuals. This finding would seem to generalize to other cultures and societies where individuals are faced with repeated crises and traumatic experiences in their environments, economic or otherwise.

Hypothesis 2: Gender will demonstrate an interaction effect with organizational factors and sector in predicting career satisfaction.

The major finding related to Hypothesis 2 was a significant relationship between secure attachment, gender, and career satisfaction, although no significant interaction effects were found to be significant. One of the novel findings from this study relates to the positive and significant relationship between insecure-dismissing attachment and career satisfaction, but the lack of an interaction effect with gender, although different than what has been reported in Western cultures, does find support in cross-cultural research not based in Western, more individualistic cultures Previous research, has reported significant gender differences in attachment patterns (Ardenghi et al., 2020; Brennan et al., 1991; Monteoliva et al., 2012), with men exhibiting greater levels of insecure-dismissing attachment. Yet, research from nonWestern cultures suggests that this distinction may not represent a cross-culturally valid finding (Schmitt, 2003).

We suggest one explanation for the nonsignificant findings related to gender differences in insecure-dismissing attachment and career satisfaction relates to the cultural context of participants. Specifically, in cultures that place a high value on collectivism, like Turkey, support seeking in difficult and stressful situations, as characteristic of individuals scoring high on secure attachment, may be lower with insecure-dismissing attachment and represent a reflection of a broader-based coping strategy. In such a context, ego-protective dynamics, as evinced with insecure-dismissing attachment, would function to promote well-being when faced with broaderbased social stressors. Schmitt (2003), in a cross-cultural study of 62 cultures, suggested that a lack of gender differences in insecure-dismissing attachment may be more ecologically and economically based rather than representing a fundamental gender difference. Thus, while individuals high in secure attachment would demonstrate greater social support seeking when dealing with problems, individuals high in insecure-dismissing attachment may be less willing to do so, and instead, rely on ego-protective mechanisms (Wise \& Mengüç, 2021). 


\section{Contributions of the Current Study}

The contribution of this study to the current literature consists, first, of the finding that secure attachment levels in adulthood predict career satisfaction for workers in Turkey beyond what has been traditionally seen as determining factors in career satisfaction (e.g., salary, promotion opportunities). Securely attached individuals demonstrate several characteristics that translate to jobrelated success, including more positive interpersonal relationships (Scrima et al. 2015), problem-solving competence (Arslan et al., 2012), hierarchical navigation (Ronen \& Zuroff, 2017), and problem-focused coping strategies (Johnstone \& Feeney, 2015). In contexts with challenging economic situations and repeated exposure to social stresses related to ongoing and chronic economic pressure, individuals scoring higher on measures of secure attachment in adulthood are more likely to show the least amount of distress and exhibit better adjustment.

While insecure-avoidant and insecure-fearful attachment scores were not predictive of career satisfaction, there was a demonstrated relationship with insecure-dismissing attachment. Considering the overlap in the ego-protective dynamics in both secure and dismissing attachment, it is suggested that individuals scoring higher on the dismissing attachment dimension may experience emotional and cognitive protection from difficult work-related experiences, even though this protection may come at the cost of poorer physical health and long-term outcomes. Our findings related to dismissing attachment scores and career satisfaction suggest a connection with research demonstrating ego-protective functions and resiliency among low-SES individuals facing traumatic experiences, both chronic and acute, insofar as economic crises are considered as traumatic inputs into the work-life of an individual. This finding may generalize beyond Turkey and suggest unique dynamics between adult attachment patterns and workplace and career experiences within economies demonstrating instability of employment, inflation, and organizational disruption related to economic crises, as demonstrated globally during the COVID19 pandemic.

Further, results in the current study did not point to any gender-based difference in career satisfaction among participants. As discussed above, this finding is similar to research on gender differences in job and career satisfaction conducted cross-culturally but does differ from previous research examining gender differences in Turkey. This is partly due to the economic status of the participants in this study, as previous research in Turkey demonstrating a gender difference in satisfaction levels has derived largely from middle- and lower-SES groups. The current sample consisted entirely of middle to upper-SES employed individuals and as such, findings are similar to previous studies in Western countries. A final contribution of the current study relates to the translation and validation of the Career Satisfaction Scale in Turkish, which provides researchers across different disciplines with a new instrument to study adults in workplace settings. 


\section{Limitations and Implications for Future Research}

The correlational and cross-sectional nature of the study does not allow for statements of causality, but the causal precedence in the variable sequence is suggestive. Self-report measures are vulnerable to response bias as the self-assessment methods assess the explicit level of the internal representation of an individual and results should be interpreted with this in mind. Third, although attachment style has been indicated as a universal domain of individual differences, the measure may demonstrate cross-cultural differences related to attachment styles and organization satisfaction, although findings in Turkey do suggest strong similarities with previous research (Sumer \& Gungor, 1999).

These findings highlight some potentially fruitful directions for future inquiry, including how different organizational cultures may maximize employee success and productivity through recognition of motivational elements in work performance. Recognition of employee psychological dispositional characteristics, including personality and attachment behaviors, can assist human resource managers and organizational support systems to integrate diverse employee background characteristics into workplace culture to promote greater organizational success. More importantly, however, is the recognition that factors beyond the organizational context influence employee career satisfaction, and by extension, employee success, in an intersectional dynamic reflecting the person-environment fit between individual-level attachment variability and macro-level structural forces.

Funding No funding was received for this research study at any stage.

Data Availability The datasets generated during and/or analyzed during the current study are not publicly available due to the possibility that information could compromise research participant privacy/consent, but are available from the corresponding author on reasonable request.

\section{Declarations}

Conflict of Interest The authors declare that they have no conflict of interest.

Informed Consent All participants completed an informed consent specifying their participation was voluntary and anonymous and explained the possible risks and benefits of participation.

\section{References}

Agishtein, P., \& Brumbaugh, C. (2013). Cultural variation in adult attachment: The impact of ethnicity, collectivism, and country of origin. Journal of Social, Evolutionary, and Cultural Psychology, 7(4), 384-405. https://doi.org/10.1037/h0099181

Ainsworth, M., Blehar, M., Waters, E., \& Wall, S. (1978). Patterns of Attachment: A psychological study of the Strange Situation. Erlbaum.

Alkhelil, A. H. (2016). The relationship between personality traits and career choice: A case study of secondary school students. International Journal of Academic Research in Progressive Education and Development, 5(2), 139-152. https://doi.org/10.6007/IJARPED/v5-i2/2132 
Amati, V., Meggiolaro, S., Rivellini, G., \& Zaccarin, S. (2018). Social relations and life satisfaction: The role of friends. Genus, 74(1), Article 7. https://doi.org/10.1186/s41118-018-0032-z

Anh, N., Nguyen, N.-M.T., Anh, N. T. T., \& Nguyen, P. M. T. (2019). Job satisfaction in developing countries: An evidence from a matched employer-employee survey in Vietnam. Journal of Economic Studies, 46(1), 192-210. https://doi.org/10.1108/JES-04-2017-0096

Ardenghi, S., Rampoldi, G., Bani, M., \& Strepparava, M. G. (2020). Attachment styles as predictors of self-reported empathy in medical students during pre-clinical years. Patient Education and Counseling, 103(5), 965-970.

Arslan, E., Arslan, C., \& Ari, R. (2012). An investigation of interpersonal problem-solving approaches with respect to attachment styles. Educational Sciences: Theory and Practice, 12(1), 15-23.

Aryee, S., \& Luk, V. (1996). Work and nonwork influences on the career satisfaction of dual-earner couples. Journal of Vocational Behavior, 49(1), 38-52. https://doi.org/10.1006/jvbe.1996.0032

Bargsted, M., Yeves, J., Merino, C., \& Venegas-Muggli, J. I. (2021). Career success is not always an outcome: Its mediating role between competence employability model and perceived employability. Career Development International, 26(2), 119-139. https://doi.org/10.1108/CDI-06-2020-0141

Barnett, R. B., \& Bradley, L. (2007). The impact of organizational support for career development on career satisfaction. Career Development International, 12(7), 617-636. https://doi.org/10.1108/ 13620430710834396

Barrick, M., \& Mount, M. (1991). The big five personality dimensions and job performance: A metaanalysis. Personnel Psychology, 44, 1-26. https://doi.org/10.1111/j.1744-6570.1991.tb00688.x

Bartholomew, K., \& Horowitz, L. M. (1991). Attachment Styles among young adults: A test of a fourcategory model. Journal of Personality and Social Psychology, 61(2), 226-244. https://doi.org/10. 1037/0022-3514.61.2.226

Bartlett, M. S. (1954). A further note on the multiplying factors for various chi-square approximations in factor analysis. Journal of the Royal Statistical Society, Series B, 16, 296-298.

Bartley, M., Head, J., \& Stansfeld, S. (2007). Is attachment style a source of resilience against health inequalities at work? Social Science \& Medicine, 64(4), 765-775. https://doi.org/10.1016/j.socsc imed.2006.09.033

Blustein, D. L., Pauling, M. L., DeMania, M. E., \& Faye, M. (1994). Relation between exploratory and choice factors and decisional progress. Journal of Vocational Behavior, 44(1), 75-90. https://doi. org/10.1006/jvbe.1994.1005

Blustein, D. L., Prezioso, M. S., \& Schultheiss, D. P. (1995). Attachment theory and career development: Current status and future directions. The Counseling Psychologist, 23(3), 416-432. https://doi.org/ $10.1177 / 0011000095233002$

Bogaerts, S., Kunst, M. J. J., \& Winkel, F. W. (2009). Dismissive attachment and posttraumatic stress disorder among Belgium securely and insecurely attached security workers. Psychological Reports, 105(12), 889-899.

Bowlby, J. (1986). Attachment, life-span, and old-age. In J. Munnichs \& B. Miesen (Eds.), Attachment, Life-Span, and Old-Age (pp. 9-19). Van Loghum Slaterus.

Bozkurt, V., Aytaç, S., Bondy, J. \& Emirgil, F. (2011). Job satisfaction, role overload and gender in Turkey. Istanbul Journal of Sociological Studies, O(44), 49-68.

Brennan, K. A., Shaver, P. R., \& Tobey, A. E. (1991). Attachment styles, gender and parental problem drinking. Journal of Social and Personal Relationships, 8(4), 451-466. https://doi.org/10.1177/ 026540759184001

Butler, E. A., Lee, T. L., \& Gross, J. J. (2007). Emotion regulation and culture: Are the social consequences of emotion suppression culture-specific? Emotion, 7(1), 30-48. https://doi.org/10.1037/ $1528-3542.7 .1 .30$

Cerci, P. A., \& Dumludag, D. (2019). Life satisfaction and job satisfaction among university faculty: The impact of working conditions, academic performance and relative income. Social Indicators Research, 144(2), 785-806. https://doi.org/10.1007/s11205-018-02059-8

Chen, X., Wen, B., \& Wu, Z. (2021). An empirical study of workplace attachment in tourism scenic areas: The positive effect of workplace fun on voluntary retention. Asia Pacific Journal of Tourism Research, 26(5), 579-596. https://doi.org/10.1080/10941665.2021.1887304

Chui, W.-Y., \& Leung, M.-T. (2016). Adult attachment internal working model of self and other in Chinese culture: Measured by the Attachment Style Questionnaire-Short Form (ASQ-SF) by confirmatory factor analysis (CFA) and item response theory (IRT). Personality and Individual Differences, 96, 55-64. https://doi.org/10.1016/j.paid.2016.02.068 
Cobb, R. J., \& Davila, J. (2009). Internal working models and change. In J. H. Obegi \& E. Berant (Eds.), Attachment theory and research in clinical work with adults (pp. 209-233). The Guilford Press.

Cohen, J. (1977). Statistical power analysis for the behavioral sciences (Rev. ed.). Lawrence Erlbaum Associates, Inc.

Coifman, K. G., Bonanno, G. A., Ray, R. D., \& Gross, J. J. (2007). Does repressive coping promote resilience? Affective-autonomic response discrepancy during bereavement. Journal of Personality and Social Psychology, 92(4), 745-758. https://doi.org/10.1037/0022-3514.92.4.745

Cömert, H., \& Yeldan, E. (2018). A tale of three crises in Turkey: 1994, 2001 and 2008-09 (No. 1809). ERC-Economic Research Center, Middle East Technical University.

Cranshaw, J., \& Game, A. (2010). Organizational career management: The role of line manager caregiving and employee relational models. Paper presented at the 70th Annual Meeting of the Academy of Management, Montreal, Canada.

Doinita, N. E., \& Maria, N. D. (2015). Attachment and parenting styles. Procedia: Social and Behavioral Sciences, 203, 199-204. https://doi.org/10.1016/j.sbspro.2015.08.282

Ein-Dor, T., Reizer, A., Shaver, P. R., \& Dotan, E. (2012). Standoffish perhaps, but successful as well: Evidence that avoidant attachment can be beneficial in professional tennis and computer science. Journal of Personality, 80(3), 749-768. https://doi.org/10.1111/j.1467-6494.2011.00747.x

Elliot, A. J., \& Reis, H. T. (2003). Attachment and exploration in adulthood. Journal of Personality and Social Psychology, 85(2), 317. https://doi.org/10.1037/0022-3514.85.2.317

Erez, A., Mikulincer, M., van Ijzendoorn, M., \& Kroonenberg, P. (2008). Attachment, personality, and volunteering: Placing volunteerism in an attachment theoretical framework. Personality and Individual Differences, 44(1), 64-74. https://doi.org/10.1016/j.paid.2007.07.021

Faupel-Badger, J.M., Nelson, D.E., \& Izmirlian, G. (2017). Career satisfaction and perceived salary competitiveness among individuals who completed postdoctoral research training in cancer prevention. PLOS ONE 12(1), Article e0169859. https://doi.org/10.1371/journal.pone.0169859

Faul, F., Erdfelder, E., Lang, A.-G., \& Buchner, A. (2007). G*Power 3: A flexible statistical power analysis program for the social, behavioral, and biomedical sciences. Behavior Research Methods, 39(2), 175-191. https://doi.org/10.3758/bf03193146

Fraley, R. C., Davis, K. E., \& Shaver, P. R. (1998). Dismissing-avoidance and the defensive organization of emotion, cognition, and behavior. In J. A. Simpson \& W. S. Rholes (Eds.), Attachment Theory and Close Relationships (pp. 249-279). Guilford Press.

Fraley, R. C., \& Shaver, P. R. (2008). Attachment theory and its place in contemporary personality theory and research. In O. P. John, R. W. Robins, \& L. A. Pervin (Eds.), Handbook of Personality: Theory and Research (pp. 518-541). Guilford Press.

Furnham, A., \& Fudge, C. (2008). The five-factor model of personality and sales performance. Journal of Individual Differences, 29(1), 11-16. https://doi.org/10.1027/1614-0001.29.1.11

Geller, D., \& Bamberger, P. (2009). Bringing attachment and anxiety to the job: Attachment style and instrumental helping behavior among co-workers. Human Relations, 62(12), 1803-1827. https:// doi.org/10.1177/0018726709337524

Galatzer-Levy, I. R., \& Bonanno, G. A. (2013). Heterogeneous patterns of stress over the four years of college: Associations with anxious attachment and ego-resiliency. Journal of Personality, 81(5), 476-486. https://doi.org/10.1111/jopy.12010

Gould, S., \& Penley, L. E. (1984). Career strategies and salary progression: A study of their relationships in a municipal bureaucracy. Organizational Behavior and Human Performance, 34(2), 244-265. https://doi.org/10.1016/0030-5073(84)90006-0

Graves, L. M., Ruderman, M. N., Ohlott, P. J., \& Weber, T. J. (2012). Driven to work and enjoyment of work: Effects on managers' outcomes. Journal of Management, 38(5), 1655-1680. https://doi.org/ $10.1177 / 0149206310363612$

Greenhaus, J. H., Parasuraman, S., \& Wormley, W. M. (1990). Effect of race on organizational experiences, job performance, evaluations and career outcomes. Academy of Management Journal, 33(1), 64-68. https://doi.org/10.2307/256352

Gnilka, P. B., Ashby, J. S., \& Noble, C. M. (2013). Adaptive and maladaptive perfectionism as mediators of adult attachment styles and depression, hopelessness, and life satisfaction. Journal of Counseling \& Development, 91(1), 78-86. https://doi.org/10.1002/j.1556-6676.2013.00074.x

Griffin, D. W., \& Bartholomew, K. (1994). The metaphysics of measurement: The case of adult attachment. Attachment processes in adulthoodIn K. Bartholomew \& D. Perlman (Eds.), Advances in personal relationships (Vol. 5, pp. 17-52). Jessica Kingsley Publishers. 
Hammami, A., Moldovan, R., \& Peltier, E. (2020). Salary perception and career prospects in audit firms. Managerial Auditing Journal, 35(6), 759-793. https://doi.org/10.1108/MAJ-11-2019-2475

Hardy, G. E., \& Barkham, M. (1994). The relationship between interpersonal attachment styles and work difficulties. Human Relations, 47(3), 263-281. https://doi.org/10.1177/001872679404700302

Harms, P. D. (2011). Adult attachment styles in the workplace. Human Resource Management Review, 21(4), 285-296. https://doi.org/10.1016/j.hrmr.2010.10.006

Hay Group. (2014). Liderlik için Türkiye'de en iyi şirketler [Best companies for leadership in Turkey]. Hay Group Istanbul Publications.

Hayden, M. C., Müllauer, P. K., \& Andreas, S. (2017). A systematic review on the association between adult attachment and interpersonal problems. Journal of Psychology \& Psychotherapy, 7(2), 1-9. https://doi.org/10.4172/2161-0487.1000296

Hazan, C., \& Shaver, P. R. (1987). Romantic love conceptualized as an attachment process. Journal of Personality and Social Psychology, 52, 511-524. https://doi.org/10.1037//0022-3514.52.3.511

Hazan, C., \& Shaver, P. R. (1990). Love and work: An attachment -theoretical perspective. Journal of Personality and Social Psychology, 59(2), 270-280. https://doi.org/10.1037/0022-3514.59.2.270

Hazan, C., \& Shaver, P. R. (1994). Attachment as an organizational framework for research on close relationships. Psychological Inquiry, 5(1), 1-22. https://doi.org/10.1207/s15327965pli0501_1

Heslin, P. A., \& Turban, D. B. (2016). Enabling career success as an emergent process. Organizational Dynamics, 45(3), 155-164. https://doi.org/10.1016/j.orgdyn.2016.07.001

Hofstede, G. (2011). Dimensionalizing cultures: The Hofstede model in context. Online Readings in Psychology and Culture, 2(1). https://doi.org/10.9707/2307-0919.1014

Hogan, J., \& Holland, B. (2003). Using theory to evaluate personality and job-performance relations: A socioanalytic perspective. Journal of Applied Psychology, 88, 100-112. https://doi.org/10.1037/ 0021-9010.88.1.100

He, Z., Zhou, Y., Li, F., Rao, Z., \& Yang, Y. (2021). The effect of proactive personality on college students' career decision-making difficulties: Moderating and mediating effects. Journal of Adult Development, 28(2), 116-125. https://doi.org/10.1007/s10804-020-09359-9

Henrich, J., Heine, S., \& Norenzayan, A. (2010). The weirdest people in the world? Behavioral and Brain Sciences, 33(2-3), 61-83. https://doi.org/10.1017/S0140525X0999152X.

Hodson, R. (1989). Gender differences in job satisfaction: Why aren't women more dissatisfied? The Sociological Quarterly, 30(3), 385-399. https://doi.org/10.1111/j.1533-8525.1989.tb01527.x

Hudson, D. L. (2013). Attachment theory and leader-follower relationships. The Psychologist-Manager Journal, 16(3), 147-159. https://doi.org/10.1037/mgr0000003

IBM Corp. Released 2013. IBM SPSS Statistics for Windows, Version 22.0. Armonk, NY: IBM Corp.

Illies, M. Y., \& Reiter-Palmon, R. (2020). The effect of perceived values on negative mentoring, organizational commitment, job satisfaction, and perceived career success. International Journal of Evidence-Based Coaching and Mentoring, 18(1), 20-30. https://doi.org/10.24384/q242-8973

Iqbal, M. S., Al-Saikhan, F. I., Ahmed, N. J., \& Iqbal, M. Z. (2020). Predictors of job and workplace satisfaction among community Pharmacists. Journal of Pharmaceutical Research International, 32(3), 78-85. https://doi.org/10.9734/jpri/2020/v32i330416

Jaracz, M., Rosiak, I., Bertrand-Bucińska, A., Jaskulski, M., Nieżurawska, J., \& Borkowska, A. (2017). Affective temperament, job stress and professional burnout in nurses and civil servants. PLoS One, 12(6), Article e0176698. https://doi.org/10.1371/journal.pone.0176698

Johnson, H. M., Irish, W., Strassle, P. D., Mahoney, S. T., Schroen, A. T., Josef, A. P., ... \& Brownstein, M. R. (2020). Associations between career satisfaction, personal life factors, and work-life integration practices among US surgeons by gender. JAMA Surgery, 155(8), 742-750https://doi.org/10. 1001/jamasurg.2020.1332

Johnstone, M., \& Feeney, J. A. (2015). Individual differences in responses to workplace stress: The contribution of attachment theory. Journal of Applied Social Psychology, 45(7), 412-424. https://doi. org/10.1111/jasp. 12308

Kağnıcioğlu, D. (2017). The role of women in working life in Turkey. WIT Transactions on Ecology and the Environment, 226, 349-358. https://doi.org/10.2495/SDP170301

Kagitcibasi, C., \& Ataca, B. (2005). Value of children and family change: A three-decade portrait from Turkey. Applied Psychology: An International Review, 54(3), 137-317. https://doi.org/10.1111/j. 1464-0597.2005.00213.x

Kagitcibasi, C., Ataca, B., \& Diri, A. (2005). The Turkish family and value of children: Trends over time. In G. Trommsdorff \& B. Nauck (Eds.), The value of children in cross-cultural perspective (pp. 91-120). Pabst Science. 
Kaiser, H. F. (1974). An index of factorial simplicity. Psychometrika, 39(1), 31-36.

Kara, D., Kim, H. L., Lee, G., \& Uysal, M. (2018). The moderating effects of gender and income between leadership and quality of work life (QWL). International Journal of Contemporary Hospitality Management, 30(3), 1419-1435. https://doi.org/10.1108/IJCHM-09-2016-0514

Karapınar, P. B. (2015). Developing trust in principal: Its relationship with attachment styles. Hacettepe University Journal of Education [hacettepe Üniversitesi Ĕ̈itim Fakültesi Dergisi], 30(3), 73-86.

Kenessey, Z. (1987). The primary, secondary, tertiary and quaternary sectors of the economy. Review of Income and Wealth, 33(4), 359-385. https://doi.org/10.1111/j.1475-4991.1987.tb00680.x

Ketterson, T. U., \& Blustein, D. L. (1997). Attachment relationships and the career exploration process. The Career Development Quarterly, 46(2), 167-178. https://doi.org/10.1002/j.2161-0045.1997. tb01003.x

Klaic, A., Burtscher, M. J., \& Jonas, K. (2018). Person-supervisor fit, needs-supplies fit, and team fit as mediators of the relationship between dual-focused transformational leadership and well-being in scientific teams. European Journal of Work and Organizational Psychology, 27(5), 669-682. https://doi.org/10.1080/1359432X.2018.1502174

Krauz, M., Bizman, A., \& Braslavsky, D. (2001). Effects of attachment style on preferences for and satisfaction with different employment contracts: An exploratory study. Journal of Business and Psychology, 16(2), 299-316. https://doi.org/10.1023/A:1011169419048

Krueger, P., Brazil, K., Lohfeld, L., Edward, H. G., Lewis, D., \& Tjam, E. (2002). Organization specific predictors of job satisfaction: Findings from a Canadian multi-site quality of work life cross-sectional survey. BMC health services research, 2(1), Article 6. https://doi.org/10.1186/1472-6963-2-6

Leiter, M. P., Day, A., \& Price, L. (2015). Attachment styles at work: Measurement, collegial relationships, and burnout. Burnout Research, 2(1), 25-35. https://doi.org/10.1016/j.burn.2015.02.003

Leenders, M. V. E., Buunk, A. P., \& Henkens, K. (2017). The role of the relationship with parents with respect to work orientation and work ethic. The Journal of General Psychology, 144, 1634. https:// doi.org/10.1080/00221309.2016.1258386

Lévy-Garboua, L., \& Montmarquette, C. (2004). Reported job satisfaction: What does it mean? The Journal of Socio-Economics, 33(2), 135-151. https://doi.org/10.1016/j.socec.2003.12.017

Lin, H. H., Chew, P. Y. G., \& Wilkinson, R. B. (2017). Young adults' attachment orientations and psychological health across cultures: The moderating role of individualism and collectivism. Journal of Relationships Research, 8, E17. https://doi.org/10.1017/jrr.2017.17

Littman-Ovadia, H., Oren, L., \& Lavy, S. (2013). Attachment and autonomy in the workplace: New insights. Journal of Career Assessment, 21(4), 502-518. https://doi.org/10.1177/1069072712 475282

Lowman, R. L. (1993). The Inter-Domain Model of career assessment and counseling. Journal of Counseling \& Development, 71(5), 549-554. https://doi.org/10.1002/j.1556-6676.1993.tb02240.x

Main, M., \& Hesse, E. (1990). Parents' unresolved traumatic experiences are related to infant disorganized attachment status: Is frightened and/or frightening parental behavior the linking mechanism? In M. T. Greenberg, D. Cicchetti, \& E. M. Cummings (Eds.), Attachment in the preschool years: Theory, research, and intervention (pp. 161-182). The University of Chicago Press.

Manning, T. T. (2003). Leadership across Cultures: Attachment Style Influences. Journal of Leadership \& Organizational Studies, 9(3), 20-30. https://doi.org/10.1177/107179190300900304

Martínez-León, I. M., Olmedo-Cifuentes, I., \& Ramón-Llorens, M. C. (2018). Work, personal and cultural factors in engineers' management of their career satisfaction. Journal of Engineering and Technology Management, 47, 22-36. https://doi.org/10.1016/J.JENGTECMAN.2017.12.002

Mayseless, O., \& Popper, M. (2019). Attachment and leadership: Review and new insights. Current Opinion in Psychology, 25, 157-161. https://doi.org/10.1016/j.copsyc.2018.08.003

Meredith, P., Merson, K., \& Strong, J. (2007). Differences in adult attachment style, career choice and career satisfaction for occupational therapy and commerce students. British Journal of Occupational Therapy, 70(6), 235-242. https://doi.org/10.1177/030802260707000603

Mikulincer, M. (1995). Attachment style and the mental representations of the self. Journal of Personality and Social Psychology, 69(6), 1203-1215. https://doi.org/10.1037/0022-3514.69.6.1203

Mikulincer, M. (1998). Attachment working models and the sense of trust: An exploration of interaction goals and affect regulation. Journal of Personality and Social Psychology, 74(5), 1209-1224. https://doi.org/10.1037/0022-3514.74.5.1209

Mikulincer, M., \& Florian, V. (1995). Appraisal of and coping with a real-life stressful situation: The contribution of attachment styles. Personality and Social Psychology Bulletin, 21(4), 406-414. 
Mikulincer, M., \& Shaver, P. R. (2007). Attachment in adulthood: Structure, dynamics, and change. The Guilford Press.

Mills-Koonce, W. R., Appleyard, K., Barnett, M., Deng, M., Putallaz, M., \& Cox, M. (2011). Adult attachment style and stress as risk factors for early maternal sensitivity and negativity. Infant Mental Health Journal, 32(3), 277-285. https://doi.org/10.1002/imhj.20296.

Monteoliva, A., García-Martínez, J. M., Calvo-Salguero, A., \& Aguilar-Luzón, M. D. (2012). Differences between men and women with a dismissing attachment style regarding their attitudes and behaviour in romantic relationships. International Journal of Psychology: Journal International De Psychologie, 47(5), 335-345. https://doi.org/10.1080/00207594.2011.634007

Muller, R. T., Sicoli, L. A., \& Lemieux, K. E. (2000). Relationship between attachment style and posttraumatic stress symptomatology among adults who report the experience of childhood abuse. Journal of Traumatic Stress, 13(2), 321-332.

Myers, L. B. (2000). Identifying repressors: A methodological issue for health psychology. Psychology and Health, 15(2), 205-214. https://doi.org/10.1080/08870440008400301

Nabi, G. R. (2001). The relationship between HRM, social support and subjective career success among men and women. International Journal of Manpower, 22(5), 457-474. https://doi.org/10.1108/ EUM0000000005850

Nabi, G. R. (2003). Situational characteristics and subjective career success: The mediating role of career-enhancing strategies. International Journal of Manpower, 24(6), 653-672. https://doi.org/ $10.1108 / 01437720310496148$

Neustadt, E., \& Furnham, A. (2006). Attachment at Work. In A. Columbus (Ed.), Advances in psychology research, (Vol. 43, pp. 155-177). Nova Science Publishers.

Nickerson, A. B., \& Nagle, R. J. (2005). Parent and peer attachment in late childhood and early adolescence. Journal of Early Adolescence, 25(2), 223-249. https://doi.org/10.1177/0272431604274174

Harma, M., \& Sümer, N. (2016). Are avoidant wives and anxious husbands unhappy in a collectivist context? Dyadic associations in established marriages. Journal of Family Studies, 22(1), 63-79. https://doi.org/10.1080/13229400.2015.1024711

Moghadam, M., Rezaei, F., Ghaderi, E., \& Rostamian, N. (2016). Relationship between attachment styles and happiness in medical students. Journal of Family Medicine and Primary Care, 5(3), 593-599. https://doi.org/10.4103/2249-4863.197314

Nae, E. Y., \& Choi, B. K. (2022). Career satisfaction, subjective well-being and turnover intention: An attachment style perspective. Baltic Journal of Management, 17(1), 1-17. https://doi.org/10.1108/ BJM-03-2021-0084

Oh, E.-J., \& Sung, K.-M. (2011). Nurses' organizational commitment, job satisfaction and job stress according to their adult attachment styles. Journal of East-West Nursing Research, 17(2), 117-124. https://doi.org/10.14370/jewnr.2011.17.2.117

Onadiran, O., \& Arogundade, O. (2021). Influence of pay and career satisfaction on employee's turnover intention in a Nigerian techie start-up. Journal of Behavioural Studies, 3(1), 44-58.

Özdin, S., \& Bayrak Özdin, Ş. (2020). Levels and predictors of anxiety, depression and health anxiety during COVID-19 pandemic in Turkish society: The importance of gender. International Journal of Social Psychiatry, 66(5), 504-511. https://doi.org/10.1177/0020764020927051

Palomar, L. J. (2008). Poverty, stressful life events, and coping strategies. The Spanish Journal of Psychology, 11(1), 228-249. https://doi.org/10.1017/s1138741600004273

Park, Y. (2018). Empirical investigation on the predictors of career satisfaction. Industrial and Commercial Training, 50(4), 165-171. https://doi.org/10.1108/ICT-03-2018-0032

Perera, H. N., Granziera, H., \& McIlveen, P. (2018). Profiles of teacher personality and relations with teacher self-efficacy, work engagement, and job satisfaction. Personality and Individual Differences, 120, 171-178. https://doi.org/10.1016/j.paid.2017.08.034

Pistole, M. C. (1993). Attachment relationships: Self-disclosure and trust. Journal of Mental Health Counseling, 15(1), 94-106.

Player, D., Youngs, P., Perrone, F., \& Grogan, E. (2017). How principal leadership and person-job fit are associated with teacher mobility and attrition. Teaching and Teacher Education, 67, 330-339. https://doi.org/10.1016/j.tate.2017.06.017

Redmond, P., \& McGuinness, S. (2017). The Gender Wage Gap in Europe: Job Preferences, Gender Convergence and Distributional Effects, IZA Discussion Papers, No. 10933, Institute of Labor Economics (IZA), Bonn

Redmond, P., \& McGuinness, S. (2020). Explaining the gender gap in job satisfaction. Applied Economics Letters, 27(17), 1415-1418. https://doi.org/10.1080/13504851.2019.1686111 
Rholes \& Simpson, (2004). Fraley, R. C., \& Brumbaugh, C. (2004). A dynamical systems approach to understanding stability and change in attachment security. In W. S. Rholes \& J. A. Simpson (Eds.), Adult attachment: Theory, research, and clinical implications (pp. 86-132). New York: Guilford Press.

Richards, D. A., \& Hackett, R. D. (2012). Attachment and emotion regulation: Compensatory interactions and leader-member exchange. The Leadership Quarterly, 23(4), 686-701. https://doi.org/10. 1016/j.leaqua.2012.03.005

Richards, D., \& Schat, A. (2007). Emotional and behavioral consequences of attachment in the workplace. Paper presented at the Annual Meeting of the Academy of Management, Philadelphia, PA.

Richards, D. A., \& Schat, A. C. (2011). Attachment at (not to) work: Applying attachment theory to explain individual behavior in organizations. Journal of Applied Psychology, 96(1), 169. https:// doi.org/10.1037/a0020372

Ripski, M. B., LoCasale-Crouch, J., \& Decker, L. (2011). Pre-service teachers: Dispositional traits, emotional states, and quality of teacher-student interactions. Teacher Education Quarterly, 38(2), 77-96.

Ronen, S., \& Zuroff, D. C. (2017). How does secure attachment affect job performance and job promotion? The role of social-rank behaviors. Journal of Vocational Behavior, 100, 137-148. https://doi. org/10.1016/j.jvb.2017.03.006

Rothbaum, F., Weisz, J., Pott, M., Miyake, K., \& Morelli, G. (2000). Attachment and culture: Security in the United States and Japan. American Psychologist, 55(10), 1093-1104. https://doi.org/10.1037/ 0003-066X.55.10.1093

Schmitt, D. P. (2003). Are men universally more dismissing than women? Gender differences in romantic attachment across 62 cultural regions. Personal Relationships, 10(3), 307-331. https://doi.org/10. $1111 / 1475-6811.00052$

Scrima, F., Di Stefano, G., Guarnaccia, C., \& Lorito, L. (2015). The impact of adult attachment style on organizational commitment and adult attachment in the workplace. Personality and Individual Differences, 86, 432-437. https://doi.org/10.1016/j.paid.2015.07.013

Spurk, D., Abele, A. E., \& Volmer, J. (2011). The career satisfaction scale: Longitudinal measurement invariance and latent growth analysis. Journal of Occupational and Organizational Psychology, 84(2), 315-326. https://doi.org/10.1111/j.2044-8325.2011.02028.x

Spurk, D., Abele, A. E., Volmer, J. (2015). The career satisfaction scale in context: A test for measurement invariance across four occupational groups. Journal of Career Assessment, 23(2), 191-209. https://doi.org/10.1177/2F1069072714535019

Sharif, S. P., Amiri, M., Allen, K.-A., Nia, H. S., Fomani, F. K., Matbue, Y. H., Goudarzian, A. H., Arefi, S., Yaghoobzadeh, A., \& Waheed, H. (2021). Attachment: The mediating role of hope, religiosity, and life satisfaction in older adults. Health and Quality of Life Outcomes, 19, Article 57. https:// doi.org/10.1186/s12955-021-01695-y

Shechtman, Z., \& Rybko, J. (2004). Attachment style and observed initial self-disclosure as explanatory variables of group functioning. Group Dynamics: Theory, Research, and Practice, 8(3), 207-220. https://doi.org/10.1037/1089-2699.8.3.207

Sheinbaum, T., Kwapil, T. R., Ballespí, S., Mitjavila, M., Chun, C. A., Silvia, P. J., \& Barrantes-Vidal, N. (2015). Attachment style predicts affect, cognitive appraisals, and social functioning in daily life. Frontiers in Psychology, 6, 296. https://doi.org/10.3389/fpsyg.2015.00296

Simmons, B. L., Gooty, J., Nelson, D. L., \& Little, L. M. (2009). Secure attachment: Implications for hope, trust, burnout, and performance. Journal of Organizational Behavior, 30(2), 233-247. https://doi.org/10.1002/job.585

Simpson, J. A., \& Rholes, W. S. (2017). Adult attachment, stress, and romantic relationships. Current Opinion in Psychology, 13, 19-24. https://doi.org/10.1016/j.copsyc.2016.04.006

Sorensen, N., \& Oyserman, D. (2010). Collectivism, effects on relationships. In H. T. Reis \& S. K. Sprecher (Eds.), Encyclopedia of human relationships (pp. 233-236). SAGE Publications.

Steel, P., Schmidt, J., Bosco, F., \& Uggerslev, K. (2019). The effects of personality on job satisfaction and life satisfaction: A meta-analytic investigation accounting for bandwidth-fidelity and commensurability. Human Relations, 72(2), 217-247. https://doi.org/10.1177/0018726718771465

Strand, P. S., Vossen, J. J., \& Savage, E. (2019). Culture and child attachment patterns: A behavioral systems synthesis. Perspectives on Behavior Science, 42(4), 835-850. https://doi.org/10.1007/ s40614-019-00220-3 
Sui, L., Qin, H., Ned, J., \& Sun, L. (2021). Personality traits and job exploration among Latino business students: An exploratory investigation. Psychology in the Schools, 58(1), 18-32. https://doi.org/10. 1002/pits. 22434

Sumer, C. H., \& Knight, P. A. (2001). How do people with different attachment styles balance work and family? A personality perspective on work-family linkage. Journal of Applied Psychology, 86(4), 653-663. https://doi.org/10.1037/0021-9010.86.4.653

Sumer, N., \& Gungor, D. (1999). Yetişkin bağlanma stilleri ölçeklerinin Türk örneklemi üzerinde psikometrik değerlendirmesi ve kültürlerarası bir karşılaştırma. Türk Psikologlar Dergisi, 14(43), 71-106.

Sunar, D. (2009). Mothers' and fathers' child-rearing practices and self-esteem in three generations of urban Turkish families. In S. Bekman \& A. Aksu-Koc (Eds.), Perspectives on human development, family and culture (pp. 126-139). Cambridge University Press.

Sunar, D., \& Fişek, E. (2005). Contemporary Turkish families. In U. Gielen \& J. Roopnarine (Eds.), Families in global perspective (pp. 169-183). Allyn \& Bacon/Pearson.

Sürücü, L. \& Maslakç1, A. (2020). Validity and reliability in quantitative research. Business \& Management Studies: An International Journal 8(3): 2694-2726. https://doi.org/10.15295/bmij.v8i3.1540

Sylva, H., Mol, S. T., Den Hartog, D. N., \& Dorenbosch, L. (2019). Person-job fit and proactive career behaviour: A dynamic approach. European Journal of Work and Organizational Psychology, 28(5), 631-645. https://doi.org/10.1080/1359432X.2019.1580309

Deveci Şirin, H., \& Şen Doğan, R. (2021). Psychometric Properties of the Turkish Version of the Experiences in Close Relationships-Relationship Structures Questionnaire (ECR-RS). SAGE Open. https://doi.org/10.1177/21582440211006056

Telsiz, M. (1998). Adolescents' views on the parental roles: A Turkish study. International Journal of Sociology of the Family, 28(2), 69-77.

Ulu, I. P., \& Tezer, E. (2010). Adaptive and maladaptive perfectionism, adult attachment, and big five personality traits. The Journal of Psychology, 144(4), 327-340. https://doi.org/10.1080/00223 981003784032

Tziner, A., Ben-David, A., Oren, L., \& Sharoni, G. (2014). Attachment to work, job satisfaction and work centrality. Leadership \& Organization Development Journal, 35(6), 555-565. https://doi.org/10. 1108/LODJ-08-2012-0102

Underwood, R., Mohr, D., \& Ross, M. (2016). Attachment style, leadership behavior, and perceptions of leader effectiveness in academic management. The Journal of Leadership Education, 15(4), 100116. https://doi.org/10.12806/v15/i4/r7

van Dolen, W., Lemmink, J., de Ruyter, K., \& de Jong, A. (2002). Customer-sales employee encounters: A dyadic perspective. Journal of Retailing, 78(4), 265-279. https://doi.org/10.1016/S00224359(02)00067-2

Vasquez, K., Durik, A. M., \& Hyde, J. S. (2002). Family and work: Implications of adult attachment styles. Personality and Social Psychology Bulletin, 28(7), 874-886. https://doi.org/10.1177/01461 6720202800702

Vîrgă, D., Schaufeli, W. B., Taris, T. W., van Beek, I., \& Sulea, C. (2019). Attachment styles and employee performance: The mediating role of burnout. The Journal of Psychology, 153(4), 383401. https://doi.org/10.1080/00223980.2018.1542375

Wise, R. M., \& Mengüç, L. (2021). The association of emotional intelligence and functional coping strategies with depression, anxiety, and stress during the COVID-19 pandemic: Evidence from Turkey. Middle East Journal of Positive Psychology, 7, 41-64.

Wright, S. L., \& Perrone, K. M. (2010). An examination of the role of attachment and efficacy in life satisfaction. The Counseling Psychologist, 38(6), 796-823. https://doi.org/10.1177/0011000009 359204

Wright, S. L., Firsick, D. M., Kacmarski, J. A., \& Jenkins-Guarnieri, M. A. (2017). Effects of attachment on coping efficacy, career decision self-efficacy, and life satisfaction. Journal of Counseling \& Development, 95(4), 445-456. https://doi.org/10.1002/jcad.12159

Yean, T. F., \& Yahya, K. K. (2013). The influence of human resources management practices and career strategy on career satisfaction of insurance agents. International Journal of Business and Society, 14(2), 193-206.

Yang, H., Miao, D., Zhu, X., Sun, Y., Liu, X., \& Wu, S. (2008). The influence of a pay increase on job satisfaction: A study with the Chinese army. Social Behavior and Personality: An International Journal, 36(10), 1333-1339. https://doi.org/10.2224/sbp.2008.36.10.1333 
Yusof, R., Mokhtar, M., Sulaiman, S. N. A., \& Mohtar, M. (2020). Consistency between personality career interest with sciences field among gifted and talented students. Journal for the Education of Gifted Young Scientists, 8(3), 1147-1161. https://doi.org/10.17478/jegys.667323

Zhang, Y., Liu, G., Zhang, L., Xu, S., \& Cheung, M.W.-L. (2021). Psychological ownership: A metaanalysis and comparison of multiple forms of attachment in the workplace. Journal of Management, 47(3), 745-770. https://doi.org/10.1177/0149206320917195 